\title{
Self-management experiences among middle-aged population of rural area of Pakistan with type 2 diabetes: A qualitative analysis
}

\author{
Rashid M. Ansari*, Hassan Hosseinzadeh, Mark Harris, Nicholas Zwar \\ School of Public Health and Community Medicine, Faculty of Medicine, UNSW, Australia
}

\section{A R T I C L E I N F O}

\section{Keywords:}

Self-management

Type 2 diabetes

Qualitative analysis

Gender

Middle-aged population

\begin{abstract}
A B S T R A C T
Background: The purpose of this research work is to explore the patients' perceptions and experiences of selfmanagement of diabetes in the rural area of Pakistan and to better understand differences in diabetes selfmanagement among men and women living with type 2 diabetes mellitus as well as the barriers and challenges of self-management of diabetes.

Methods: 30 participants were recruited from a medical centre at Al-Rehman hospital at Abbottabad, Pakistan. Qualitative method was used to conduct interviews of $n=30$ patients with Type 2 diabetes using a semistructured interview approach with audio recording to explore their perceptions and experiences of the selfmanagement of type 2 diabetes and the factors that influence the management of diabetes.

Results: The qualitative analyses revealed six themes: stigma attached to the disease; self-management in context; patient-doctor relationship; adherence to diet and exercise; access to diabetes resources; and social support. Women were more adaptable to diabetic conditions, disclosed their diabetes more readily and are a lot more ready to integrate management into their daily lives, whereas men were more reluctant to tell friends and family about their diabetes due to the stigma attached to the disease and were less observant of self-management practices in social settings. Women used socially interactive resources such as internet access and education classes whereas men relied more on self-directed learning and wanted the guidance of health professionals. Finally, both men and women reported lack of support from the health care practitioners and families in managing their diabetes.

Conclusions: The results of this qualitative research highlighted the challenges of diabetes self-management among men and women in the rural area of Pakistan and barriers to self-management. These findings may help to inform gender-sensitive diabetes self-management approach, diabetes awareness in the population, counselling and support.
\end{abstract}

\section{Introduction}

Diabetes mellitus is a pandemic disease and one of the leading threats to human health. ${ }^{1}$ As estimated by the International Diabetes Federation (IDF) in 2014 that there are a total of 371 million people suffering from diabetes in the world. ${ }^{2}$ The estimate also showed that the disease accounted for approximately 4.8 million deaths. According to International Diabetes Federation ${ }^{2},{ }^{3}$ the Type 2 diabetes is more prevalent among people aged between 40 and 59 years. Type 2 diabetes is a major public health problem in Pakistan especially among middleaged population. This population is at high risk of type 2 diabetes because people are more likely to be overweight or obese, physically inactive and have unhealthy eating habits. ${ }^{4-6}$ For instance, recent large population-based studies found that $35 \%$ Pakistani population are overweight or obese. ${ }^{1},^{2}$

The current literature reveals that diabetes self-management is the cornerstone of diabetes care. ${ }^{7}$ There are several studies ${ }^{8}, 9$ that have reported that diabetes self-management is associated with improved diabetes knowledge, self-management behaviours and clinical outcomes. Fisher et al. ${ }^{10}$ suggested that the quality clinical care and selfmanagement are compatible and dependent on each. Therefore, in the absence of sound care, individual's efforts may be misdirected, and expert clinical care will fall far short of its potential.

In diabetes management, patients may fail to use prescribed medications to control the blood sugar or to implement the management plans. ${ }^{10}$ One of the factors that are critical for the maintenance of the behaviour changes is the availability of the required resources (10). Therefore, there is a need for all the required resources to be integrated

\footnotetext{
Abbreviations: IDF, International Diabetes Federation; HbA1c, glycosylated haemoglobin

* Corresponding author at: Building 226, Al-Khobar 76810, 31952, Saudi Arabia.

E-mail addresses: dr.ansarirm@yahoo.com (R.M. Ansari), h.hosseinzadeh@unsw.edu.au (H. Hosseinzadeh), m.f.harris@unsw.edu.au (M. Harris), n.zwar@unsw.edu.au (N. Zwar).
} 
in order to achieve the benefits associated with self-management. Wagner et al. ${ }^{11}$ provided a framework for integrating the resources and supports for self-management with key components of clinical care in a chronic care model. A number of studies have also suggested that patients' understanding and beliefs about health and illness may be shaped by historical and local contexts; ${ }^{12}$ whether respondents are thinking about health or behaviours in general or about their own ${ }^{13}$ and personal experience and observation.

Generally, it is agreed that self-management of a chronic disease is significant in controlling and preventing complications associated with the disease. Despite the benefits associated with self-management of diabetes, research has shown that most patients do not adhere to selfmanagement recommendations. ${ }^{14-16}$ Adherence to the recommendations and barriers are both problematic for "lifestyle" behaviours such as eating patterns and physical activity rather than medication adherence. $^{4-6}$ This is evident from the culture, tradition and lifestyle behaviour of the people of Pakistan, where the eating patterns and physical activities are posing a lot of difficulties to the middle-aged population in the self-management of diabetes. ${ }^{4}$

One of the major challenges that have been cited by most scholars is psychological barriers. According to Shera et al., ${ }^{17}$ psychosocial barriers influences longer-term outcomes, such as glycemic control (HbA1c) and eventually the development of diabetes complications. In addition, cultural barriers have been cited as another challenge that affects the implementation of diabetes self-management programmes. In Pakistan, the middle-aged population has both psychosocial and cultural barriers to their diabetes management. ${ }^{17} \mathrm{~A}$ review of related literature $^{14-22}$ revealed that non-compliance to healthy eating requirements, lack of physical activity, lack of family and cultural support and difficulties in accessing medical care are some of the barriers to self-management of diabetes.

The primary aim of this study is to explore and determine the factors contributing to the optimal self-management skills among middle-aged Type 2 diabetes patients of the rural area of Pakistan. This novel study aimed to understand from an individual point of view, the patient's perceptions and experiences of self-management as well as potential barriers to self-management. Embedded in this study are a number of distinct objectives: (1) to explore how the health issue related to diabetes is viewed and addressed individually and in the community of Pakistan, (2) to explore the factors affecting self-management practices in Pakistan.

This study is based on the qualitative design during the exploration of qualitative studies ${ }^{23}$ and guided by the results of the systematic review of self-management of type 2 diabetes which has identified six major themes. ${ }^{24}$ These themes are (1) the stigma attached to the disease (disclosure as a person living with diabetes), (2) self-management in context, (3) patient-doctor relationship, (4) adherence to diet and exercise, (5) diabetes resources and (6) social support and will also explore the factors affecting the patient's self-management activities including the barriers to self-management. This approach will allow us to understand the issues and problems related to self-management of diabetes and life experiences of the middle-aged population of the rural area of Pakistan.

\section{Materials and methods}

\subsection{Qualitative design}

Ansari et al. ${ }^{23}$ explored the qualitative research on diabetes selfmanagement in middle-aged population of rural area of Pakistan. This design uses those concepts to explore patients' perceptions and experiences of self-management of their diabetes in Pakistan. This approach explored the gaps between the physician-patient understanding and the socio-demographic differences in the self-management of type 2 diabetes. This study identified the barriers to self-management and captured the uniqueness of the individual, feelings, behaviours and experiences of managing diabetes.

This design was guided by the results of systematic review of selfmanagement of type 2 diabetes carried out by the same authors ${ }^{24}$ and highlighted five factors which are most important to influence the diabetes self-management. The authors mentioned that factors such as socio-demographic characteristics, behavioural and psychological characteristics, social support, barriers to self-management and cultural characteristics have significant impact on the self-management activities carried out by the middle-aged population of Pakistan. ${ }^{25}$ The authors have also highlighted the importance of these factors particularly barriers to self-management of type 2 diabetes. ${ }^{26}$

The data collected on these issues were analysed by thematic analysis. According to Creswell, ${ }^{27}$ qualitative study approach allows for rich, in-depth understanding through a holistic framework and, therefore, most suited to answer the proposed research questions in this study.

\subsection{Sampling method}

The study sample was restricted to the patients enrolled in the Primary Health Care Centre of Al-Rehman Hospital of the rural area of Pakistan. Purposive sampling technique was used for the selection of the patients. This sampling technique allows recruiting patients who are more likely to participate in a semi-structured interview session. A purposive sample of 30 patients was selected from the 50 participants. According to Palinkas et al., ${ }^{28}$ purposive sampling is a suitable sampling method in qualitative studies to identify and select information-rich respondents to a phenomenon of interest which was the self-management of diabetes mellitus in this study. Therefore, this sampling approach will be used to determine the sample size based on theoretical saturation, a point during data collection when new data does not bring additional insights to the research question. ${ }^{28}$

Palinkas et al. ${ }^{28}$ also argued that purposive sampling is the most successful if the data review and analysis are done together with data collection. Therefore, this sampling method ensured adequate data collection, analysis and review. A small sample size $(n=30$ diabetic patients) allowed an in-depth exploration of the experiences of patients regarding the self-management of type 2 diabetes. Lawton et al. ${ }^{29}$ selected a sample size of 32 participants for their qualitative analysis in open ended interviews. Therefore, this sample size is appropriate for the purpose of this study.

\subsection{Research participants}

The middle-aged population aged 40-60 years were included with poorly controlled type 2 diabetes - in line with the highest number of diabetic patients within the age groups of 40-59 years reported by International Diabetes Federation (IDF). The initial contact with the potential participants was made by the medical director of the Hospital. The participants visiting the centre were provided with the initial feedback about the scope of the study. The consent to participate in the study was obtained with an option to withdraw at any time. The patients with diabetes having HbA1c $>7.0 \%$ were included in this study and patients having coexisting liver, kidney or thyroid disorder were excluded. Also, the patients with cognitive impairment, or major psychiatric diagnosis, or surgery were excluded.

\subsection{Consent to participate}

The participants were provided a written consent in the form of an Information Sheet and consent form before the actual interviews were carried out. The English version of the information sheet and consent form was translated into participants' native language. Since the researcher speaks the same language, an interpreter was not required. This written method approach of consent is more appropriate for that specific population as the translation of information sheet and the 
Table 1

General Overview of the Study Design for Qualitative Research.

\begin{tabular}{|c|c|c|c|c|}
\hline Design & Goal & $\begin{array}{l}\text { Sample } \\
\text { Size (n) }\end{array}$ & $\begin{array}{l}\text { Sampling and } \\
\text { location }\end{array}$ & $\begin{array}{l}\text { Analysis } \\
\text { Methods }\end{array}$ \\
\hline $\begin{array}{l}\text { Qualitative } \\
\text { Research }\end{array}$ & $\begin{array}{l}\text { - Exploring the } \\
\text { self- management } \\
\text { activities of } \\
\text { patients of type } 2 \\
\text { diabetes } \\
\text { - Exploring factors } \\
\text { that affect } \\
\text { patients' self- } \\
\text { management }\end{array}$ & $\begin{array}{l}\mathrm{n}=30 \\
\text { patients }\end{array}$ & $\begin{aligned} \text { - Purposive } & \\
\text { - Primary } & \text { Health Care } \\
& \text { (medical } \\
& \text { Clinic) }\end{aligned}$ & $\begin{array}{l}\text { Thematic } \\
\text { Analysis }\end{array}$ \\
\hline
\end{tabular}

consent form in their language provided accurate information. The audio recording was used during semi-structured interviews, translated into English and subsequently transcribed into Nvivo 11 Pro.

Following the initial data collection, all identifying information of the participants was removed and objective identifiers were used on the transcripts to ensure anonymity. Transport was arranged for all the participants coming from long distances and healthy lunch was provided every time they visited the clinic on the invitation for face-to-face interview and instructions. A gift voucher of 1000 PKR (equivalent A \$15) was given to participants at the end of the interviews to reimburse them for their time. A general overview of the data collection approach for 30 participants and the study design for qualitative research are given in Table 1.

\section{Qualitative data analysis}

In-depth, semi-structured face-to-face $40 \mathrm{~min}$ interviews of the 30 patients diagnosed with diabetes took place in a clinical setting at Medical Centre in Abbottabad, Pakistan to explore their perceptions and experiences of the self-management of type 2 diabetes and the factors that influence the management of diabetes.

In this study, the thematic analysis of data was adopted for analyzing the data because the method was developed to meet the needs of investigating the experiences, meaning and reality of the participants. ${ }^{30}$ Thematic analysis is widely used in qualitative research and is an analytical tool used to identify, analyze and report themes within the data. ${ }^{31}$ There are six stages to complete this method as shown in Fig. 1.

\section{Data familiarization}

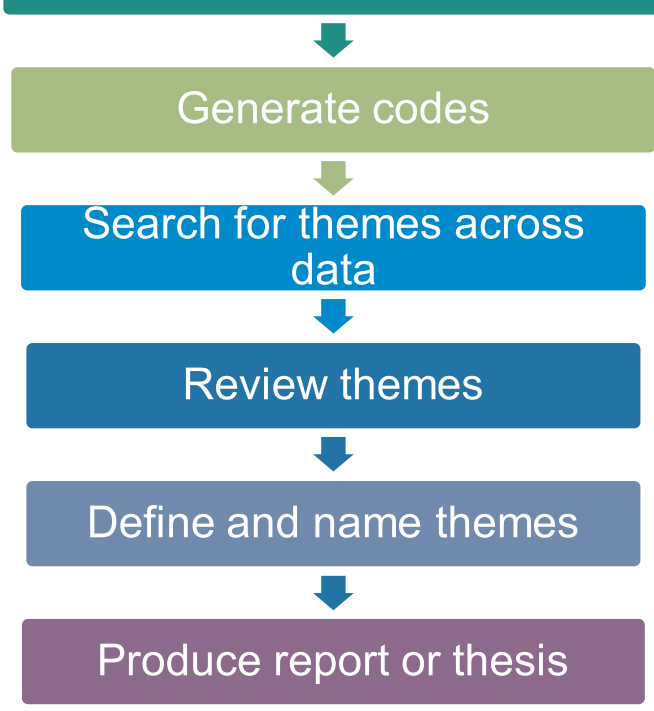

Fig. 1. Six steps of Thematic Analysis framework.
The research team addressed issues of rigor and trustworthiness based on a quality framework outlined by Meyrick. ${ }^{32}$ Our research team composed of three academics expert in diabetes, one local practice diabetes expert and the researcher. The researcher carried out the individual interviews but the transcripts had all identifying information removed so that we were able to maintain confidentiality and anonymity during analysis. Our data analysis was made inductively as we created initial themes without having a coding scheme in place.

The thematic analysis was used to explore salient topics that emerged from the interviews. ${ }^{33}$ Our thematic analysis involved initial independent coding by three academics. Seventy codes were identified in the preliminary analysis of the transcripts. Codes were then clustered and used to form 10 preliminary sub-themes that integrated several of the originally identified codes and encompassed more general topics that were the focus of the transcripts. The detailed analysis led to the six major themes that illustrated the most significant and broad similarities or differences of diabetes self-management experiences and barriers to self-management. These themes are further elaborated in the following section of results.

\section{Results}

The participants' demographics are provided in Table 2 . There were a total of 30 participants and the average age of the participants was 58 years (range 40-60 years), 15 men and 15 women participated with a mean duration of time since diagnosis of type 2 diabetes was 10 years. The data analysis yielded six emergent themes across varying contexts on self-management of diabetes and barriers to self-management. These themes were further divided across socio-demographic differences and highlighted in Table 3.

Table 2

The summary of participants demographics $(\mathrm{n}=30)$.

\begin{tabular}{|c|c|c|c|}
\hline Demographic & Men $(n=15)$ & $\begin{array}{l}\text { Women } \\
(n=15)\end{array}$ & $\begin{array}{l}\text { Total } \\
(n=30)\end{array}$ \\
\hline Age (average, in years) & 62 & 55 & 58 \\
\hline \multicolumn{4}{|l|}{$\begin{array}{l}\text { Marital Status (number of } \\
\text { participants) }\end{array}$} \\
\hline Single/never married & 4 & 3 & 7 \\
\hline Married & 7 & 8 & 15 \\
\hline Separated/divorced & 4 & 2 & 6 \\
\hline Widowed & 0 & 2 & 2 \\
\hline Unreported & 0 & 0 & 0 \\
\hline \multicolumn{4}{|l|}{$\begin{array}{l}\text { Education (number of } \\
\text { participants) }\end{array}$} \\
\hline Less than grade 9 & 3 & 2 & 5 \\
\hline $\begin{array}{l}\text { Some/completed high } \\
\text { school }\end{array}$ & 5 & 8 & 13 \\
\hline $\begin{array}{l}\text { Some/completed college or } \\
\text { university }\end{array}$ & 5 & 4 & 9 \\
\hline $\begin{array}{l}\text { Graduate/professional } \\
\quad \text { degree }\end{array}$ & 2 & 1 & 3 \\
\hline Unreported & 0 & 0 & 0 \\
\hline \multicolumn{4}{|l|}{$\begin{array}{l}\text { Employment (number of } \\
\text { participants) }\end{array}$} \\
\hline $\begin{array}{l}\text { Full/part-time, self- } \\
\text { employed }\end{array}$ & 10 & 9 & 19 \\
\hline Unemployed & 2 & 5 & 7 \\
\hline Retired & 3 & 0 & 3 \\
\hline Student & 0 & 0 & 0 \\
\hline Unreported & 0 & 1 & 1 \\
\hline \multicolumn{4}{|l|}{ Family background } \\
\hline Languages spoken at home & $\begin{array}{l}\text { Urdu/Punjabi } \\
\text { Pushto }\end{array}$ & $\begin{array}{l}\text { Urdu/Punjabi } \\
\text { Pushto }\end{array}$ & - \\
\hline Cultural Background & $\begin{array}{l}\text { Mohajir/ } \\
\text { Punjabi and } \\
\text { Pathan }\end{array}$ & $\begin{array}{l}\text { Mohajir/ } \\
\text { Punjabi and } \\
\text { Pathan }\end{array}$ & - \\
\hline
\end{tabular}


Table 3

The summary of six emergent themes from data analysis.

\begin{tabular}{|c|c|c|c|c|c|c|}
\hline Socio-Demo. & Stigma of disease & Self-mgmt. in context & Patient-doctor relationship & $\begin{array}{l}\text { Adherence to diet and } \\
\text { exercise }\end{array}$ & Diabetes resources & Social support \\
\hline Men & Kept diagnosis Secret & $\begin{array}{l}\text { Not regularly carried } \\
\text { out }\end{array}$ & Conflict with doctors & $\begin{array}{l}\text { Not in social gatherings \& } \\
\text { functions }\end{array}$ & Independent resources & Support from spouse \\
\hline Women & $\begin{array}{l}\text { Open to discussion about } \\
\text { diabetes }\end{array}$ & $\begin{array}{l}\text { Many barriers - joint } \\
\text { family }\end{array}$ & $\begin{array}{l}\text { More expectations from } \\
\text { doctors }\end{array}$ & $\begin{array}{l}\text { Difficulties -Family } \\
\text { restrictions }\end{array}$ & Lack of support & $\begin{array}{l}\text { Less support - joint } \\
\text { family }\end{array}$ \\
\hline
\end{tabular}

\subsection{Stigma attached to the disease}

Diabetes is considered "self-inflicted disease" in Pakistan - a moral aspect to self-management of diabetes. However, due to lack of education and awareness about diabetes in that country, this gap is widened and poses a great challenge to overcome. I found during interviews that women were more open to express that they have diabetes and let their family members know about it as well. One woman participant said:

"There is no point hiding the disease from the family as we live in the same house or in the same family environment, so it will be revealed anyway as there are not many choices to eat different foods than what a non-diabetic person is eating in the family".

However, men were reluctant to let the family know about the diagnosis. Although, conflicting reasons were given to me why men wanted to hide the diagnosis but my overall impression was that they feel "guilty" as the majority of people in Pakistan (rural or urban areas) consider that the diabetes illness is self-inflicted. One male participant mentioned:

"I don't want people to know that I have diabetes as people start to look down on me, considering that I have done something wrong in my past life".

\subsection{Self-management in context}

In Pakistan, women often subjugated their own needs to those of other family members, usually husbands and children, who preferred non-diabetic foods. The men in that society, by contrast, viewed dietary change as a matter for their wives who were allocated the task of serving the "right" foods. Therefore, the men resisted shaping their own identity to the requirements of diabetes management by shifting the responsibility on others. One woman said in the interview:

"I cook the food according to the choices of the family - I don't have much to say on the choice of the food, so I have no idea how to manage my diabetes in relation to healthy food choices".

The differences in the experiences of men and women, as identified in the literature, demonstrate that diabetes self-management has a gendered dimension. In particular, in the context of Pakistan, the structure of gender roles within the family often meant that in comparison to men, women's effort to "self-manage" were less likely to be supported by children and male partners, who were often unwilling to adopt diabetic-friendly diets.

The importance of the relative positions of men and women were acknowledged by Whittemore et al. ${ }^{34}$ who suggested that women are primarily responsible for family meals and for overall family health. Therefore, the diabetes self-management targeting women might be particularly fruitful. Hence, the social and historical positioning of women as caregivers for children and husbands has an impact on how diabetes management is understood and enacted by the whole family.

Some of the participants during the interviews expressed a view of their families as instrumental in offering emotional and practical support in living with diabetes, they have also noted problematic aspects of the collectivist context. These included placing the needs of the families above requirements for illness management and postponing self-management strategies to take part in traditional celebrations involving food.

The participants described their cultural context in which immediate and extended families were viewed as a source of support. In addition, participants mentioned that:

"On some special events, refusing unhealthy food to eat or bringing diabetes -appropriate food to such events would be considered rude to the hosts and would not be accepted".

The lack of understanding of diabetes self-management exists in Pakistani cultures which might have constraining effects to the selfmanagement of diabetes.

There is also a strong moral aspect to self-management because deteriorating health due to diabetes is linked to a failing self, in particular a failure to self-control. It was also noted by Broom and Whittaker ${ }^{35}$ that such understandings undermine the efforts of health professionals in managing diabetes.

\subsection{Patient-doctor relationship}

The social interaction between the patients and doctors is of great significance in the self-management of type 2 diabetes. The diabetic patients need to engage with a range of health professionals in order to develop and participate in self-management activities. ${ }^{36}$ The participants expressed disappointment in relation to the doctors and their approach towards the patients.

For example, one participant elaborated: "I have acted on the advice of my doctor all the time, but continued to experience deterioration in my health condition - my diabetes was not in control, so I decided not to follow the doctor's recommendations, and hence, decided not to adhere to dietary and behavioural recommendations".

The other participant was not happy with the doctor's attitude and said that:

"I went to see a doctor after my blood test results came from the laboratory to discuss the future plan to manage my diabetes and the doctor started blaming me for the high HbA1c results and mentioned that I was not following his instructions".

\subsection{Adherence to diet and exercise}

The response of participants on diet and exercise questions was very much similar to each other. It appears though that the aspect of selfmanagement is almost missing from the population. In particular, the concept of diet and exercise was not there though some participants mentioned about walking in the evening but not regularly. This was evident from the culture, tradition and lifestyle behaviour of the people of the rural area of Pakistan where the eating patterns and physical activity are posing a lot of difficulties to the middle-aged population in the self-management of diabetes.

One of the participants said: "No diet and exercise - they eat whatever is cooked at home for the family. Physical activity is nonexistent as we don't have proper facilities in this area where we can 
safely do the physical activities".

According to Khowaja and Waheed, ${ }^{37}$ the eating behaviours of others can influence eating behaviours of diabetic patients, especially if they live together. This is the case in Pakistani society where there is a joint family living system. ${ }^{37}$ Adherence to self-management of diabetes is also affected by the resources available for the management. ${ }^{38}$ For instance, healthy eating patterns and physical activity levels are not likely to occur or persist without convenient sources of healthy foods and attractive, safe settings. Therefore, ecological perspectives are significant for the access to key resources in self-management. ${ }^{38}$

\subsection{Diabetes resources}

In Pakistan, the diabetes management programme in the community health clinics is not equipped well enough to help and support the patients with diabetes and the health services in the community are not adequate. There is a great shortage of community doctors and expensive consultations with private doctors posing many problems to patients.

One participant elaborated: "The current system of healthcare is very poor and not helping much to manage diabetes. We don't get any direction from there".

"Access to diabetes specialist doctor is not an easy task - too expensive to afford the fees. The doctor at the clinic is accessible but with long waiting period at the clinic as a lot of patients come to the clinic from other neighbouring areas".

The socio-cultural factors in Pakistan play a vital role in hampering change, especially for women, such as non-availability of socially appropriate facilities close to their homes where they can walk and exercise. It was also identified by Wang et al. ${ }^{39}$ that socio-cultural practices lead to dietary non-compliance and lack of motivation for exercise as important factors.

\subsection{Social support}

The lack of social support in that community of rural area of Pakistan was very much evident from the discussions with the patients, particularly from friends and family. That may also be considered a barrier to dietary adherence and self-management of diabetes. ${ }^{40}$ According to Brown and Hedges, ${ }^{41}$ there is evidence to show that stress, depression, low level of efficacy, lack of social and community support may have direct and indirect effects on metabolic outcome.

One of the female participants said: "Support from family members and friends is very important, however, that is not always the case. "My husband is very supportive but not his family members".

It was also noted during the interviews that participants want their doctors to support them practically and morally. They would prefer their doctors to be aware of diabetes services and resources, to be willing to coordinate these resources for them and provide consistent follow-up including glycemic control, medication adjustments, and listening to their personal stories. However, we noted differences between men and women in how participants discussed support from their families.

Most women did not mention about their spouse as a source of support to them and often felt that they were required to change their lifestyles without the help of their families. One woman described how she balanced her own healthy diet with her family's preferences, as she was the main person who was cooking for the family.

One of the female participants mentioned: "It is always difficult to cook for you or stay with your own heathy food choices in a joint family set up".

She found it extremely difficult to cook diabetic friendly food to manage her diabetes in terms of sugar control as the food choices were dictated by her joint family. Another woman described that eating different food than what everyone is eating keep you isolated from the rest of the family and friends particularly in a party or wedding functions.

\section{Discussion}

The main objective of this study was to explore diabetes self-management experiences, its challenges and barriers to self-management of type 2 diabetes in the rural area of Pakistan. The other important aspect was to see the gender differences: that is how men and women identify themselves as a person with diabetes or reveal their diagnosis to others. It was interesting to observe that women disclosed their diabetes more openly to others and practiced their self-care behaviours or activities regardless of social settings. In contrast, men were much more private in their disclosure of diabetes in social gatherings and were reluctant to discuss this matter in public. Mathew et al. ${ }^{42}$ identified the similar approach between men and women with type 2 diabetes in their studies. They found the vast differences between how men and women identify themselves as a person with diabetes and their approach to reveal their disease to others.

The nature of social support in this study also differs between men and women. It was observed that men considered their wives the main source of social support, influencing the family members adopting the lifestyle changes to make modifications in cooking diabetic friendly food at home. This was also indicated by Liburd et al. ${ }^{43}$ that wives play an important role in men's diabetes self-management activities particularly in relation to diet. However, most of the women in the study described less support from their spouses and families.

In regards to patient-doctor relationship, it was observed during the interview that majority of the patients were not happy about the fact that self-management aspect was not discussed by the doctors with them at the time of diagnosis of diabetes and illustrated that at the point of diagnosis limited significance was placed on the self-care management of type 2 diabetes.

Feudtner ${ }^{44}$ has shown evidence of "victim blaming" between doctor and patient and suggested that a "moralistic dialogue" should emerge between the two parties. The other studies carried out in Pakistan on diabetes education and awareness on self-management suggested that the level of awareness at both physicians and patients level, along with other community people has been observed to be low. ${ }^{14-22}$ It is evident from these studies that the different ways in which cultural understandings were drawn on by participants profoundly affected their approach to diabetes self-management.

This study has revealed that due to the apparent lack of significance, the participants placed on type 2 diabetes, do not sufficiently engage in appropriate self-care management. The participants did not necessarily view type 2 diabetes as a chronic condition due to experiencing little or no signs or symptoms, pre or post diagnosis. Despite the lack of full acceptance, participants passively recognized that 'something needed to be done.' Participants expressed a desire to be treated as a person with diabetes rather than the clinician's focus on treating the disease in a generic manner.

The questionnaire for this study was developed using a self-management framework by Brewer- Lowry et $a{ }^{45}$ as a guide for the interview. This framework describes self-management as a series of intersections involving various tasks (diet, physical activity, medications, foot care, and glucose monitoring at home and seeking medical care) and resources. This framework is a clear example of the multi-faceted nature of diabetes self-management. The concept of interview guides was structured to cover general information regarding daily activities or social roles that could influence self-management. This will allow the researcher to draw an overall picture of participants that is beneficial for obtaining useful information.

The other concept focuses on the experiences of the diabetic 
patients designed to follow the timeline of living with diabetes and selfmanagement, emphasizing on the impact of diabetes, barriers to selfmanagement, and coping with diabetes complications. While this model was useful in directing our interview guide, our major themes were developed based on our inductive analysis and the emerging selfmanagement issues identified by our study population. The English version of the interview guide related to patients with type 2 diabetes is given in Appendix A.

\section{Conclusions}

The results of this qualitative research highlighted the challenges of diabetes self-management among men and women in the rural area of Pakistan and barriers to self-management. The findings of this study may help to inform gender-sensitive diabetes self-management approach, diabetes awareness in the population, counselling and support. The six major themes identified in this study representing the selfmanagement practices in the middle-aged population of Pakistan were: the stigma attached to the disease, self-management in context, patientdoctor relationship, adherence to diet and exercise, diabetes resources and social support.

\section{Conflict of interest}

The authors declare that they have no conflict of interest.

\section{Funding}

No funding was received for this research work.

\section{Financial disclosure}

Authors have no financial relationships relevant to this article to disclose.

\section{Availability of data and materials}

The data sets used and analyzed during the current study are available from the corresponding author on a reasonable justification.

\section{Authors' contributions}

RA conducted the semi-structured interviews, recorded and transcribed the data. Also, analyzed and interpreted the patient data regarding the self-management of type 2 diabetes and drafted the manuscript. $\mathrm{HH}$ and $\mathrm{MH}$ reviewed the work and commented to make the modifications required. NZ reviewed the manuscript and provided his comments to enhance the overall presentation of the results. All authors read and approved the final manuscript.

\section{Ethics approval and consent to participate}

The study was approved by the ethics committee of University of New South Wales, Australia (ref: HC16882) and by Ayub Medical Institutions, Abbottabad, Pakistan from the office of the Chairman Medical Ethics Committee. Also, written consent to participate in this study was obtained from the participants using UNSW participant information statement and consent form.

\section{Consent for publication}

Consent to publication was obtained from the participants in this study.

\section{Acknowledgements}

The authors are thankful to the director of Al-Rehman hospital, Abbottabad, Pakistan facilitating the interviews and data collection activities.

Appendix A. Qualitative interview guide for patients with type 2 diabetes

- Qualitative interview guide for patients with type 2 diabetes

This list of questions has been developed to facilitate the interview for individual patients to examine the interviewee's health experiences related to self-management of type 2 diabetes and exploring the barriers to self-management.

Q1. Can you explain to me how diabetes influences your life?

Q2.Describe your overall experience managing diabetes over the past years

in relation to the following:

- Diet and nutrition

- Physical activity

- Taking medication

- Coping with and managing stress

- Symptoms and complications

Q3. What impact has having diabetes had on you over the past years?

Reflect upon the following:

- Diet: social gathering, watching what you eat

- Personal life

- Treatment

- Future complications, hyper/hypoglycemia

- Fears/anxieties

Q4. How do you feel about the healthcare you have received? Are there any issues related to:

- Quality of care

- Attitude of general practitioners

- Attitude of other healthcare professionals (nurses, dietitian etc.)

Q5. What other kinds of support and resources have been most helpful to you in managing your diabetes? [Probing on different kind of care]

- How do your family/friends help you?

- Family physician

- Books/magazines/internet

Q6 What is your experience of seeking healthcare? Probe on:

- What makes seeking healthcare easier?

- What makes it more difficult?

Q7.What is your experience accessing healthcare in regards to your diabetes?

- Visit to general practitioner

- Visit to hospital

- Visit to specialist

- Visit to diabetes education centre

Q8. In your opinion, what are the most important factors that could 
affect your diabetes self-management at home, at work or in social life? Q9. How does the current healthcare system affect your diabetes self-management?

Q10.Are there any other issues that you want to raise that we have not discussed about the self-management of diabetes?

Q11. Is there anything else you would like to tell me?

Thank you for your time and cooperation for this interview.

\section{References}

[1]. Narayan KMV. The diabetes pandemic: looking for the silver lining. Clin Diabetes. 2005;23(2):51-52.

[2]. International Diabetes Federation. Diabetes prevalence 2014. available online from: http://www.idf.org/home/index.cfm.

[3]. Whiting DR, Guariguata L, Weil C, et al. IDF diabetes atlas: global estimates of the prevalence of diabetes for 2011 and 2030. Diabetes Res Clin Pract. 2011;94:311-321 Available online from: http://www.idf.org/home/index.cfm.

[4]. Ansari RM, Hosseinzadeh H, Zwar N. Primary healthcare system of Pakistan: challenges to self-management of type 2 diabetes. Open $J$ Endocr Metab Dis. 2016;6:173-182. http://dx.doi.org/10.4236/ojemd.2016.67023.

[5]. Jafar TH, Chaturvedi N, Pappas G. Prevalence of overweight and obesity and their association with hypertension and diabetes mellitus in an Indo-Asian population. CMAJ. 2006;175(9):1071-1077.

[6]. Ansari RM. Effect of physical activity and obesity on type 2 diabetes in the middleaged population. J Environ Public Health. 2009;2009:4-9.

[7]. Chin MH, Auerbach SB, Harrison JF, et al. Quality of diabetes care in community health centres. Am J Public Health. 2000;90:431-434.

[8]. Mensing C, Boucher J, Cypress M, et al. National standards for diabetes self-management education. Diabetes Care. 2007(Suppl 1):S96-S103.

[9]. Norris SL, Lau J, Smith SJ, et al. Self-management education for adults with type 2 diabetes: a meta-analysis of the effect on glycemic control. Diabetes Care. 2002;25:1159-1171.

[10]. Fisher EB, Brownson CA, O'Toole ML, et al. Ecological approaches to self-management: the case of diabetes. Am J Public Health. 2005;95:1523-1535.

[11]. Wagner EH, Austin BT, Von Korff M. Organizing care for patients with chronic illness. Milbank Q. 1996;74:511-544.

[12]. Macfarlane A, Kelleher D. Concepts of illness causation and attitudes to health care among older people in the Republic of Ireland. Soc Sci Med. 2002;54:1389-1400.

[13]. Blaxter M. Health and lifestyles. London: Tavistock/ Routledge; 1990.

[14]. American Diabetes Association. Clinical practice recommendations 2000. Diabetes Care. 2000;23(Suppl. 1):S1-S116.

[15]. Ali M, Khalid GH, Pirkani GS. Level of health education in patients with type 2 diabetes mellitus in Quetta. J Pak Med Assoc. 1998;48:334-336.

[16]. Jabbar A, Contractor Z, Ebrahim MA, et al. Standard of knowledge about their disease among patients with diabetes in Karachi, Pakistan. J Pak Med Assoc. 2001;51(21):6-8.

[17]. Shera AS, Jawad F, Basit A. Diabetes related knowledge, attitude and practices of family physicians in Pakistan. J Pak Med Assoc. 2002;52:465-470.

[18]. Hasan ZU, Zia S, Maracy M. Baseline disease knowledge assessment in patients with type 2 diabetes in a rural area of northwest of Pakistan. J Pak Med Assoc. 2000;54:67-73.

[19]. Adil MM, Alam AY, Jeffery T. Knowledge of type 2 diabetes patients about their illness: a pilot project. J Med Assoc. 2005;55:221-224.

[20]. Sabri AA, Qayyum MA, Saigol NU, et al. Comparing knowledge of diabetes mellitus among rural and urban diabetics. McGill J Med. 2007;10:87-89.

[21]. Ulvi OS, Chaudhary RY, Ali T, et al. Investigating the awareness level about diabetes mellitus and associated factors in rural Islamabad. J Pak Med Assoc. 2009;59 798-80.
[22]. Afridi MA, Khan MN. Role of health education in the management of diabetes mellitus. J Coll Phys Surg Pak. 2003;13:558-561.

[23]. Ansari RM, Hosseinzadeh H, Zwar N. Exploring the qualitative research on diabetes self-management in middle-aged population of rural area of Pakistan. Int $J$ Public Health Epidemiol. 2016;5(7):285-291.

[24]. Ansari RM, Hosseinzadeh H, Zwar N. Systematic review of type 2 diabetes selfmanagement: focusing on the middle-aged population of rural area of Pakistan. Glob Adv Res J Med Med Sci. 2016;5(no. 6):170-182.

[25]. Ansari RM, Hosseinzadeh H, Harris M, Zwar N. Conceptual model of diabetes selfmanagement for middle-aged population of rural area of Pakistan. Int $J$ Diabetes Res. 2017;6(3):68-72.

[26]. Ansari RM, Hosseinzadeh H, Zwar N. Application of chronic care model for selfmanagement of type 2 diabetes: focus on the middle-aged population of Pakistan. Int J Med Res Pharm Sci. 2016;3(7):1-7.

[27]. Creswell J. Qualitative inquiry and research design: choosing among five traditions. thousand Oak, CA: Sage; 2007.

[28]. Palinkas LA, Horwitz SM, Green CA, et al. Purposeful sampling for qualitative data collection and analysis in mixed method implementation research. Administration and Policy in Mental Health and Mental Health Services Research; 2013:1-12.

[29]. Lawton J, Ahmad N, Hanna L, et al. 'I can't do any serious exercise': barriers to physical activity amongst people of Pakistani and Indian origin with type 2 diabetes. Health Educ Res. 2006;21(1):43-54.

[30]. Braun V, Clarke V. Using thematic analysis in psychology. Qual Res Psychol. 2006;3:77-101.

[31]. Howitt D, Cramer D. Thematic analysis: introduction to qualitative methods in psychology. 2010; 2010:163-186.

[32]. Meyrick J. A first step towards a comprehensive approach to judging rigor/quality. J Health Psychol. 2006;11(5):799-808.

[33]. Attride-Stirling J. Thematic networks: an analytic tool for qualitative research. Qual Res. 2001;1(3):385-405.

[34]. Whittemore R, Chase S, Mandle CL, et al. The content, integrity, and efficacy of a nurse coaching intervention in type 2 diabetes. Diabetes Educ. 2001;27(6):887-898.

[35]. Broom D, Whittaker A. Controlling diabetes: moral language in the management of diabetes type 2. Soc Sci Med. 2004;58(11):2371-2382.

[36]. Pendleton D, Schofield T, Tate P. The consultation: an approach to learning and teaching. Oxford: Oxford University Press; 1984.

[37]. Khowaja K, Waheed H. Self- glucose monitoring and glycemic control at a tertiary care university Hospital Karachi, Pakistan. J Pak Med Assoc. 2010;60(12):1035-1038.

[38]. Pakistan Medical Research Council. National health survey of Pakistan. Health profile of the people of Pakistan, 1990-94. Islamabad, Pakistan: Pakistan Medical Research Council; 1998

[39]. Wang CY, Abbott L, Goodbody AK, et al. Development of a community-based diabetes management program for pacific islanders. Diabetes Educ. 1999;25:738-746.

[40]. Glasgow RE, Toobert DJ, Gillette CD. Psychosocial barriers to diabetes self-management and quality of life. Diabetes Spect. 2001;14:33-41.

[41]. Brown SA, Hedges LV. Predicting metabolic control in diabetes: a pilot study using meta-analysis to estimate a linear model. Nurs Res. 1994;43:362-368.

[42]. Mathew R, Gucciardi E, De Melo E, et al. Self-Management experiences among men and women with type 2 diabetes mellitus: a qualitative analysis. BMC Fam Pract. 2012;13:122.

[43]. Liburd LC, Namageyo-Funa A, Jack L. Understanding 'Maculinity' and the challenges of managing type 2 diabetes among African-American men. $J$ Natl Med Assoc. 2007:99(5):550-558.

[44]. Feudtner CBittersweet. Diabetes, insulin and transformation of illness. Chapel Hill: University of North Caroline press; 2003.

[45]. Brewer-Lowery AN, Arcury TA, Bell RA, et al. Differentiating approaches to diabetes self-management of multi-ethnic rural older adults at the extremes of glycemic control. Gerontologist. 2010;50(5):657-667. 